\title{
STUDY OF THERMAL PROPERTIES OF LIGHTWEIGHT INSULATION MADE OF FLAX STRAW
}

\author{
Maryna BABENKO ${ }^{1 *}$, Adriana ESTOKOVA², Mykola SAVYTSKYI ${ }^{1}$, Stanislav UNČíK ${ }^{3}$
}

\begin{abstract}
The article presents the results of a study of the properties of flax straw as a raw material and as a lightweight, environmentally-friendly insulation made of a two-component mixture of flax straw and liquid glass. The flax is considered to be renewable and is a 100\% natural waste product of the agriculture industry, which may be widely used as sustainable building insulation af ter light modifications. The ratio mixes of the two-component eco-insulation of flax straw and liquid glass ( $\mathrm{Na2O}(\mathrm{SiO} 2))$ have been developed in terms of sustainability principles such as environmental friendliness and energy efficiency. We used thermal analysis to compare flax straw as a raw material, and a complex insulation made of flax straw demonstrated a slower decomposition of the composite and shorter peaks, which supports the concept of the transformation of flax straw with liquid glass to increase its fire resistance properties. The peaks of the loss of mass with the exothermal process were defined for both flax samples. The thermal conductivity coefficient of the material is around $0.085 \mathrm{~W} / \mathrm{m} \mathrm{K}$, which permits its use as an effective insulation material for sustainable buildings.
\end{abstract}

\section{Address}

1 "Prydniprovska State Academy of Civil Engineering and Architecture" State Higher Education Establishment, Ukraine, Department of Reinforced Concrete and Stone Constructions

2 Technical University of Kosice, Slovak Republic and Department of Material Engineering/Institute of Environmental Engineering, Faculty of Civil Engineering

3 Slovak University of Technology in Bratislava, Bratislava, Slovak Republic, Department of Material Engineering, Faculty of Civil Engineering

* Corresponding author: babenko.marina@yahoo.com

\section{Key words}

- Flax, straw,

- Ecological insulation,

- Energy efficiency,

- Sustainable development,

- Agriculture waste,

- Vernacular architecture.

\section{INTRODUCTION}

The history of architecture has emphasized certain "noble" materials, such as stone, iron, concrete and glass. The use of a less common and more unglamorous building resource, i.e., "waste", is currently appearing as an alternative that should not be ignored. In the context of the reuse and recycling of materials, waste has become an important input in the evaluation of contemporary vernacular and popular housing.

To give new uses to refuse is not a new idea, but its importance is increasing. The use and recycling of waste materials can be seen from two points of view: even if recycling or reusing waste materials does not solve the housing problem, the practice represents an important alternative, which has great potential as a general solution, and even if such a practice does not solve the problem of solid waste, it helps to diminish the impact of such environmental pollution. These perspectives represent two ways of improving the level and quality of the lives of thousands of people. An integral approach to the reuse and recycling of waste is useful everywhere, but its application seems to be more necessary in developing countries where both environmental and housing problems are a priority. Reuse of materials in vernacular architecture is an old tradition (Claveran, 1997).

Straw is the dried stem of wheat or other grains and is a by-product after the harvesting of the crop. From ancient times various articles made of straw have been produced all over the world. These straw products, which were produced as crafts by farmers, are not only useful goods for living but also beautiful formative arts of a high quality. Straw is an important element of vernacular architecture and has long been used as a part of building materials. In folk buildings around the world, straw has been used for roofing and to strengthen 
walls as a component of adobe. The useful parts of a length of straw are employed. The soft part, which corresponds to a blade, is used for fuel; the strong stem is used for crafts. The elastic head is especially used for brooms. At the end of their lives these products are burned and used as fuel; their ash is returned to the ground as fertilizer and as a source of the life of a future plant. Thus, from an ecological viewpoint, straw has a complete recycling system (Straw, 1997).

Every year, the European Union produces about 1.3 billion tons of waste, about 700 million tons of which constitute agricultural residues. The problems caused by disposing of these by-products of manufacturing require effective solutions. The problem of recycling these secondary products of production also requires an effective solution. To date, a significant part of agricultural waste is incinerated, which is economically inappropriate and environmentally unsafe because of the large amount of greenhouse gases incineration produces that are harmful to the environment. The depletion of some types of natural raw materials leads to the need to use waste and secondary products of production to develope new products. Today in Ukraine more than $50 \%$ of the acreage is allocated for the cultivation of grain crops, $19 \%$ of which is wheat, $11 \%$ barley and $1 \%$ rye. Industrial crops occupy about $30 \%$ of the acreage. Thus, the area for the cultivation of grain crops occupies a large part of the acreage, the use of which yields a multitude of waste in the form of a non-grain part of the crop, i.e., straw. According to our statistical data, the annual volume of straw is from 16 to 24 million tons, of which no more than $0.2 \%$ is used as industrial raw material (Savytskyi et.al, 2015). Plant materials have a number of advantages such as availability, fast renewability, a low cost, environmental friendliness, and low thermal conductivity along with the possibility of using both organic and inorganic binders. The materials obtained cover the demands of sustainability, energy efficiency, economic efficiency, and ecological compatibility. An effective and environmentally friendly solution may be found through the rational transformation of raw straw material.

The transformed materials are those materials that have been irreversibly changed from their natural "raw" state by some form of processing in order to improve their suitability for use in construction. In this sense, all manufactured materials are transformed materials, but there are some manufactured materials (in the sense of factory made), for instance, burnt bricks and tiles, which are entirely made by craftsmanship.

Natural raw materials are transformed in order to improve one or more of their inherent characteristics to make them more suitable for use in buildings. Raw materials may be transformed in order to improve their strength; durability; resistance to corrosion and weathering, rot or insect attack; resistance to fire, shape or dimensional accuracy; and dimensional stability. Their transformation is frequently carried out in order to achieve several of these improvements simultaneously. A range of different types of transformation have traditionally been used in crafts. The traditional types of transformation include firing and heating, chemical processes, the intermixing of different materials, the coating and rendering of one material with another, and compaction through the application of ramming or pressure (Spence, 1997).

The practice of using transformed plant materials and animal waste in the construction of residential buildings and industrial buildings involves a thousand-year tradition. These materials have been used in traditional buildings for the production of wall materials from adobe (straw, bonfire hemp, fire flax), the construction of roofs (straw), and finishing constructs and layers, floors and plaster (horse manure).

The development of compounds of heat-insulating materials from renewable resources of a plant origin is currently being undertaken and has a great future. For a filler straw made from cereals, hemp, and flax, is used as a binder, i.e., liquid-glass ( $\mathrm{SiO} 2 . \mathrm{H} 2 \mathrm{O})$. The sam- ples of materials obtained have a sufficiently low density and thermal conductivity, along with compressive strength at a $10 \%$ deformation, which are sufficient for the process of the transportation and installation of products. However, in order to obtain optimal compositions, a thorough study of the properties of raw materials and the process of the structural formation of heat-insulating composites, with their physico-mechanical and thermal properties, is required.

The development of materials based on vegetable fiber will help solve problems involving the use of agricultural waste and, at the same time, help obtain inexpensive and effective thermal insulation materials based on ecologically clean and quickly renewable local raw materials.

\section{LITERATURE REVIEW}

Research has been conducted on the application of flax and other straw materials used in the construction sector.

In 2015, A. Mahieu, H. Lenormand, N. Leblanc and A. Vive compared four agricultural resources through the study of the properties of $100 \%$ bio-based particleboard (hemp, flax, wheat and sunflower). The thermal conductivity measurements showed that the materials developed have interesting insulation properties. Their thermal performance is due to the natural porosity of these plant materials. The sorption measurements and mechanical properties indicate that panels made of two of the four agro-resources exhibit comparable or better performances than that of the reference material, which was prepared with wood particles and UF resin. Thus the agro-resources studied here seem to be good candidates for replacing wood for the manufacture of low-density panels (Mahieu et.al, 2015).

P.A. Chabriac, E. Gourdon and H. Fabbri Lenormand of the University of Lyon acoustically characterized five types of agricultural by-products largely used for building insulation in 2016. They showed that hemp shiv, sunflower bark and pith, flax shiv and rape straw demonstrate quite interesting sound absorption coefficients. Their absorption for a given thickness can be equivalent to typical commercial sound absorbers such as fiberglass and thus could be considered for use in green buildings. Indeed, their acoustical performance provided good reverberation characteristics, as well as a high indoor environmental quality, which is a key point in certifications such as LEED (Chabriac, 2016).

At Kazan State University in Russia, the composition and technology of pressed heat-insulating material based on chopped wheat straw (a particle length of $30-50 \mathrm{~mm}$ ) were developed. The average density of such thermal insulation board is $125-300 \mathrm{~kg} / \mathrm{m} 3$; the thermal conductivity coefficient is $0.044-0.056 \mathrm{~W} /(\mathrm{m} \cdot \mathrm{K})$; and the compressive strength with a $10 \%$ deformation is $0.3-0.8 \mathrm{MPa}$ (Petrov, 1998). Soldatov and Khozin (2013) presented a technology for the manufacture of heat-insulating material based on chopped straw (a particle length of $30-50 \mathrm{~mm}$ ) and high-modulus liquid glass. The coefficient of the thermal conductivity of the material varies from 0.048 to $0.052 \mathrm{~W} /(\mathrm{m} \cdot \mathrm{K})$ in a dry state; the compressive strength at a $10 \%$ strain is $0.22-0.24 \mathrm{MPa}$, the average density is $170-190 \mathrm{~kg} / \mathrm{m} 3$ (Soldatov and Khozin, 2013).

\section{METHODOLOGY}

The research presented was realized according to a successive approach consisting of the thermal analysis of raw flax straw material and lightweight composite flax straw insulation together with a study of the thermal properties (thermal conductivity) of lightweight composite flax straw insulation. The general schema of the research is shown in Fig. 1. 


\section{Usability of flax straw insulation}
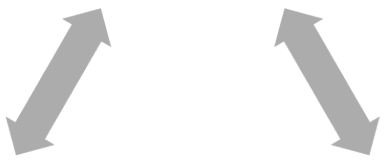

\section{Thermal analysis of flax straw insulation}

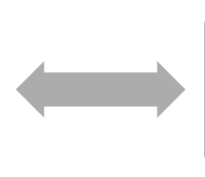

\section{Thermal properties study of flax straw insulation}

Fig. 1 General approach of the research

\subsection{Study Materials}

The lightweight flax straw insulation was manufactured in the following order: first, the straw component was carefully mixed for 2 minutes; then liquid glass $(\mathrm{Na} 2 \mathrm{O}(\mathrm{SiO} 2))$ was added; and the whole mixture was stirred for 2-3 min until a homogeneous mass was obtained. The compositions of the insulation samples are presented in Table 1.

Tab. 1 Composition of the composite mixture

\begin{tabular}{c|c|c}
\hline Composition & $\begin{array}{c}\text { Straw, } \\
\text { mass fractions }\end{array}$ & $\begin{array}{c}\text { Liquid Glass, } \\
\text { mass fractions }\end{array}$ \\
\hline flax straw insulation Л1 & 1 & 2.4 \\
\hline flax straw insulation Л2 & 1 & 2 \\
\hline
\end{tabular}

The raw material, flax straw, and flax straw insulation composite in the form of a panel are shown in Fig. 2.

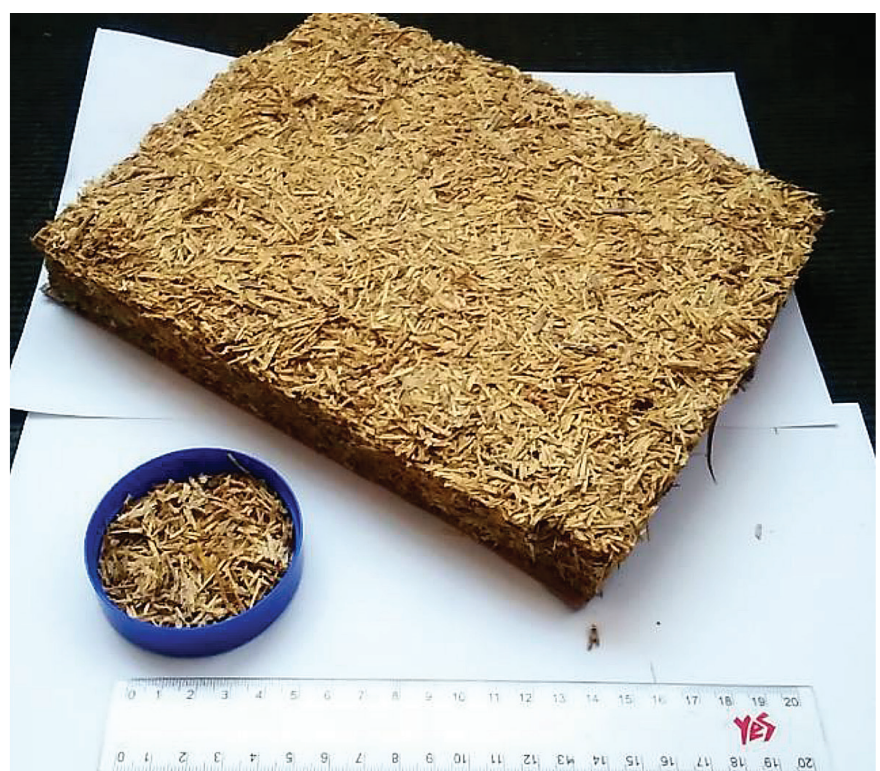

Fig. 2 Flax straw and flax straw lightweight insulation composite

\subsection{Thermal analysis}

Thermal analysis in a nitrogen environment was performed to study the mass change, thermal stability, and energy balance of the material. The measurements were realized on simultaneous Jupiter ${ }^{\circledR}$ STA 449 F3 thermal analyzers at a laboratory of the Environmental Engineering Department, Civil Engineering Faculty, TUKE (Kosice). The measurements were performed on selected samples of pure flax straw and composite flax straw insulation, and the Л1 composite mixture, using the TG/DSC mode. The samples were heated in $\mathrm{Al}_{2} \mathrm{O}_{3}$ crucibles. The parameters of the measurements are presented in Table 2 .

Tab. 2 The parameters of the thermal analysis of the straw-based lightweight concretes

\begin{tabular}{c|c|c|c|c}
\hline $\begin{array}{c}\text { Lightweight } \\
\text { concretes }\end{array}$ & $\begin{array}{c}\text { Initial } \\
\text { mass, } \\
\mathrm{mg}\end{array}$ & $\begin{array}{c}\text { Heating } \\
\text { rate, } \\
\mathrm{K} / \mathrm{min}\end{array}$ & $\begin{array}{c}\text { Temperature } \\
\text { interval, K }\end{array}$ & Atmosphere \\
\hline pure flax straw & 10.57 & 10 & $28-900$ & nitrogen \\
\hline flax straw insulation & 12.73 & 10 & $26-900$ & nitrogen \\
\hline
\end{tabular}

\section{3 Study of thermal properties}

The measurements were realized in a LM.305 Heat Flow Meter to determine the steady-state heat flow properties, thermal conductivity, and thermal resistance of the flat slab specimens in accordance with ISO 8301, EN 12667 and ASTM C518 at a laboratory of the Civil Engineering Faculty, TUKE (Kosice). The equipment, which has its own control software and acquisition data, is equipped with one fixed and one mobile plate. In the central area of each plate, the measurement zone, one heat flow meter provided with thousands of small thermocouples is embedded. The average signal of each heat flow meter is proportional to the heat flow through the specimen, and that signal is used to determine the thermal conductivity of the specimen.

The test consists of applying a temperature gradient and programming plates at different temperatures to produce a heat flow through the specimen. The differences in temperature are calculated as the difference between the temperatures measured in the center of each plate. To accurately determine the thermal conductivity of the material, it must be at a steady state, i.e., it must meet a number of criteria such as:

- Temperature criteria: the plate's temperature must be stabilized. The technical specifications of the LM.305 equipment manufacturer specify temperature fluctuations below $\pm 0.01{ }^{\circ} \mathrm{C}$.

- Criteria at the output signal for the heat flow meters: the signal of the heat meters should not vary. According to the manufacturer's specifications, the heat flow is measured with two separate sensors with a precision access of $0.01 \mathrm{~W} / \mathrm{m} 2$. (Fenollera, 2015)

In this manner, it is possible to determine the material's thermal conductivity at a steady state by using the following equation derived from Fourier's Law:

$$
\frac{d Q}{\Delta T}=\frac{\lambda}{d}=\frac{1}{R}(1)
$$

where dQ is the heat flow obtained from the calibration constants of the heat flux meters and the electrical signal provided [W/m2]; $\Delta \mathrm{T}$ is the difference in temperature established between the two sides of the specimen $[\mathrm{K}] ; \lambda$ is the specimen's thermal conductivity $[\mathrm{W} / \mathrm{mK}]$; $\mathrm{d}$ is the specimen's thickness $[\mathrm{m}]$; and $\mathrm{R}$ is the thermal resistance of the specimen $\left[\mathrm{m}^{2} \mathrm{~K} / \mathrm{W}\right]$. 
For the experimental proceedings a sample with special dimensions was manufactured according to the requirements of the equipment. The characteristics for the samples used are reflected in Table 3 . The test time for each sample was one hour (3600 s).

Tab. 3 Parameters of the sample for testing the heat flow and thermal conductibility coefficient with the LM.305 Heat Flow Meter

\begin{tabular}{c|c|c|c|c}
\hline Composition & $\begin{array}{c}\text { Width, } \\
\mathrm{mm}\end{array}$ & $\begin{array}{c}\text { Length, } \\
\mathrm{mm}\end{array}$ & $\begin{array}{c}\text { Thickness, } \\
\mathrm{mm}\end{array}$ & $\begin{array}{c}\text { Mass, } \\
\mathrm{g}\end{array}$ \\
\hline flax straw insulation Л1 & 200 & 250 & 35 & 545.5 \\
\hline flax straw insulation Л2 & 200 & 250 & 35 & 588.4 \\
\hline
\end{tabular}

\section{RESULTS}

\subsection{Thermal analysis of the flax straw insulation}

The temperatures of the thermal decomposition of the straw and composite based on the Difference Thermo Gravimetry (DTG) curves (Fig. 3), are given in Table 4.

Tab. 4 Temperature ranges of degradation components of the flax straw and lightweight insulation made of flax straw and corresponding mass losses (nitrogen)

\begin{tabular}{c|ccc}
\hline \multirow{2}{*}{ Sample } & \multicolumn{3}{|c}{$\begin{array}{c}\text { Temperature ranges of degradation of } \\
\text { components, }{ }^{\circ} \mathrm{C} \text { under nitrogen }\end{array}$} \\
\cline { 2 - 4 } & $1^{\text {st }}$ peak & $2^{\text {nd }}$ peak & Total mass loss,$\%$ \\
\hline pure flax straw & 66 & 355 & 95.56 \\
\hline flax straw insulation Л1 & 70.0 & 280 & 58.02 \\
\hline
\end{tabular}

As is shown in the DTG curves (Fig. 3), the samples decomposed in several steps. The thermal degradation of both samples was manifested by two mass-loss peaks. There was an early peak at about $66^{\circ} \mathrm{C}$ for the pure flax straw and a second peak with significant mass loss at about $355^{\circ} \mathrm{C}$. The first peak appeared at 100 ${ }^{\circ} \mathrm{C}$ for the flax insulation sample and the second peak at about $280{ }^{\circ} \mathrm{C}$. As the samples were $100 \%$ organic fully-based materials, the test demonstrates a standard picture of the decomposition of organic

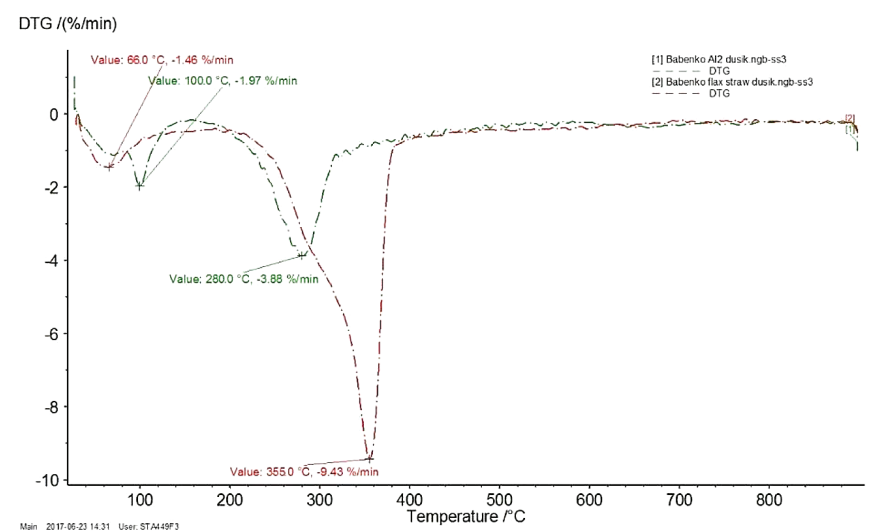

Fig. 3 DTG curves for flax straw and lightweight insulation made of flax straw compounds. The slower decomposition of the composite confirms the higher resistance of the flax treated by liquid glass. The difference in the residual masses can also result from the increased thermal resistance of flax after treating it with liquid glass, which was probably caused by mineralization of the wood-based material when treated with liquid glass (Fig. 4). The peak on the DSC of the flax with liquid glass could be linked to the decomposition of the $\mathrm{SiO} 2 \mathrm{H} 2 \mathrm{O}$ gel, which can be formed after the reaction of glass with water and $\mathrm{CO} 2$. This peak is not present on the DSC curve of the pure flax (Fig. 5).

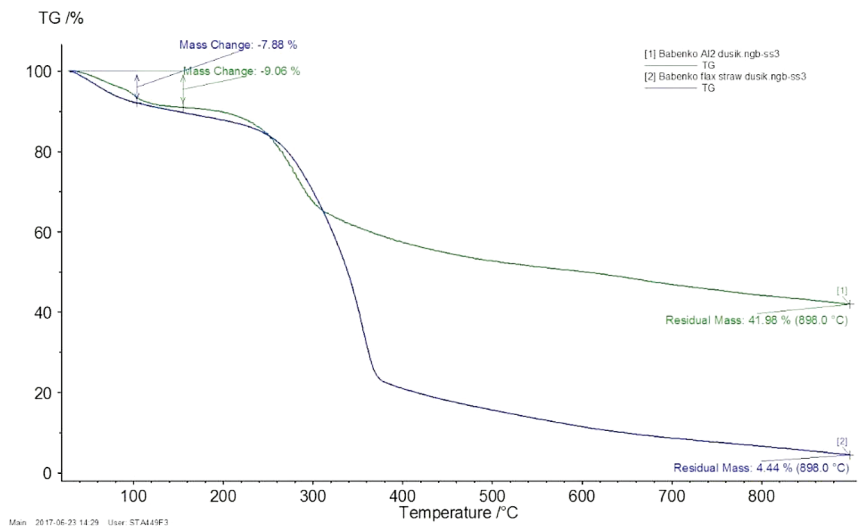

Fig. 4 Comparison of TG curves of pure flax straw and flax straw insulation

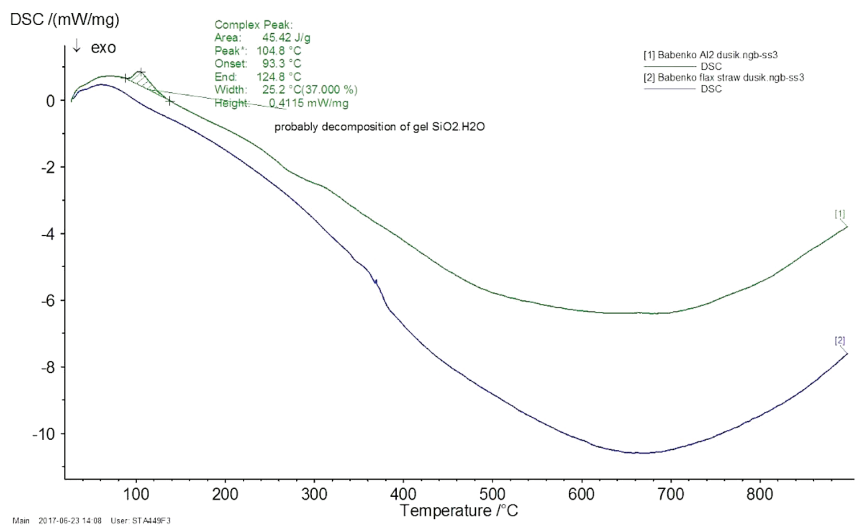

Fig. 5 Comparison of DSC curves of pure flax straw and flax straw insulation

\subsection{Study of the thermal properties of flax straw insulation}

The study of the thermal properties of the flax straw insulation was realized one time for the samples of each composition. During the first test for the flax straw insulation Л1, the upper hot plate had a temperature which was changed $20-19.85 \mathrm{~K}$; the lower cold panel had a temperature which was changed $0-8.85 \mathrm{~K}$, thus $\Delta \mathrm{T}$; the difference in temperature established between the two sides of the specimen was $11 \mathrm{~K}$. The second test for the Л 2 flax straw insulation was realized with a difference in temperature of $12.46 \mathrm{~K}$ established between the two sides of the specimen.

The final summary results are presented in Table 5 and the graphics of Fig. 6. The change in mass in the composition of the mass fraction of 0.4 did not significantly increase the thermal properties of 


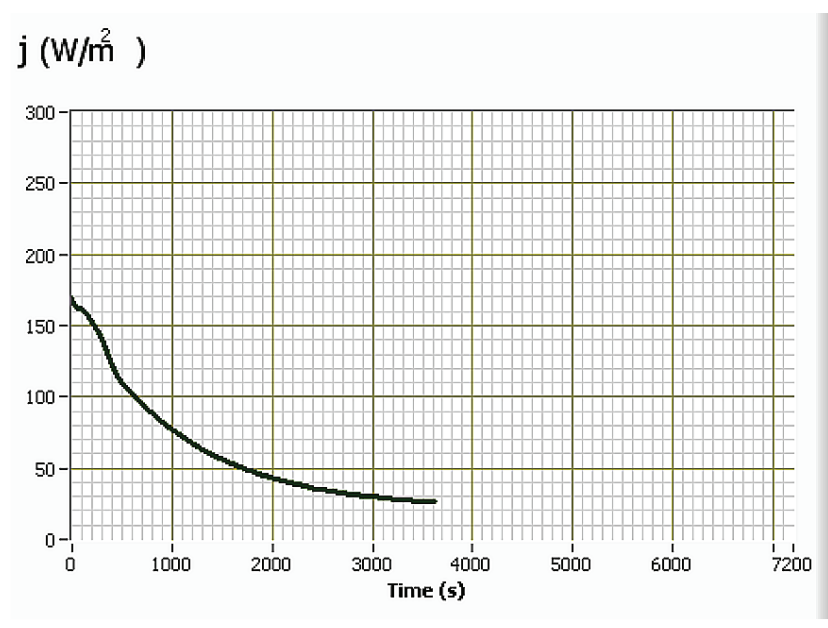

a)
$j\left(W / m^{2}\right)$

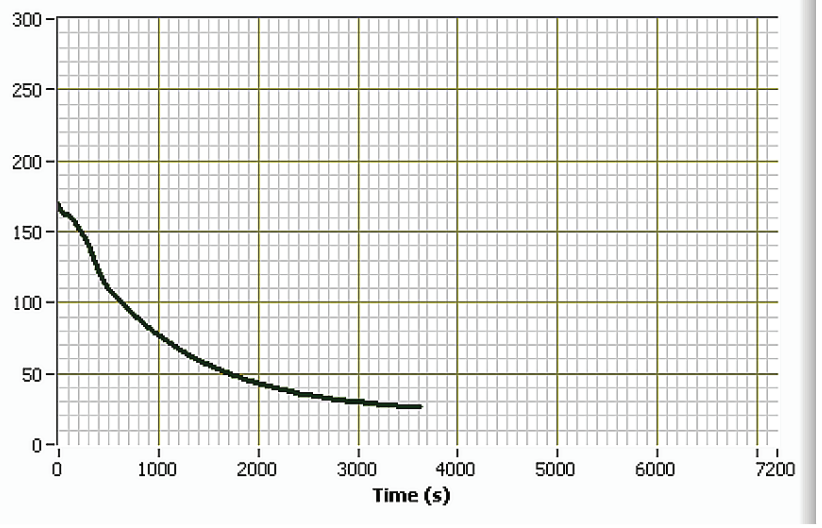

b)

Fig. 6. Heat flow diagram for lightweight insulation made of flax straw and liquid glass: a) flax straw insulation of J1 composition; b) flax straw insulation of $Л 2$ composition

the flax straw insulation. At the same time the utilization of a composition with less liquid glass can decrease its consumption by around $20 \%$, which is a positive saving economically and environmentally.

Tab. 5: Thermal properties of lightweight insulation made of flax straw and liquid glass

\begin{tabular}{c|ccc}
\hline Composition & $\begin{array}{c}\text { Density, } \\
\mathrm{kg} / \mathrm{m}^{3}\end{array}$ & $\begin{array}{c}\text { Heat flow, }(\mathrm{j}),[\mathrm{W} / \mathrm{m} 2] \\
\text { coefficient, W/m K }\end{array}$ & $\begin{array}{c}\text { Thermal } \\
\text { conductivity } \\
\text { cocion }\end{array}$ \\
\hline flax straw insulation Л1 & 311.7 & 24.416 & 0.08410 \\
\hline flax straw insulation Л2 & 336.2 & 29.904 & 0.08464 \\
\hline
\end{tabular}

\section{CONCLUSIONS}

The research presented defines the future of agricultural waste for the production of lightweight, environmentally friendly insulation material, i.e., flax straw. The properties studied of this raw material showed the effectiveness and quite high thermal properties of a $100 \%$ natural composition made from it. Its important properties as raw material, i.e., the jagged surface of the fibers and a thermal conductivity coefficient of around $0.085 \mathrm{~W} / \mathrm{m} \mathrm{K}$, permit it to be used as an effective insulation material for sustainable buildings. The ratio mixes of the two-component eco-insulation of flax straw and liquid glass $(\mathrm{Na} 2 \mathrm{O}(\mathrm{SiO} 2))$ has been developed in terms of sustainability principles such as environmental friendliness and energy efficiency. The change in the mass fraction composition of 0.4 did not significantly increase the thermal properties of the flax straw insulation. At the same time the utilization of a composition with less liquid glass can decrease its consumption to around $20 \%$, which is a positive saving economically and environmentally. During the thermal analysis flax straw as raw material and flax straw insulation were compared; the analysis showed the slower decomposition of the composite, which confirms the higher resistance of the flax treated by liquid glass. Furthermore, the slower decomposition and shorter peaks support the idea of the transformation of flax straw with liquid glass to increase its fire resistant properties. The mass loss peaks have been defined for both flax samples, which were accompanied by an exothermal process, which is a positive aspect that takes into account the life cycle of the material and the recycling stage. 


\section{REFERENCES}

Chabriac, P. A., Gourdon, E., Glé, P., Lenormand, H., Fabbri, A. (2016) Agricultural by-products for building insulation: acoustical characterization and modeling to predict micro - structural parameters, Construction and Building Materials 112, 158-167. Available from: https://www.researchgate.net/publication/296623224_Agricultural_by-products_for_building_insulation_Acoustical_characterization_and_modeling_to_predict_micro-structural_parameters [accessed Nov 10 2017].

Claveran, J. G. (1997) Waste and Re-use, Encyclopedia of vernacular architecture of the world: Theories and principles, Book 1, Paul Oliver Cambridge University Press, pp. 261-263.

Fenollera, M., Míguez, J. L., Goicoechea, I., Lorenzo, J. (2015) Experimental Study on Thermal Conductivity of Self-Compacting Concrete with Recycled Aggregate, Materials, 8, 4457-4478. Available from: https://www.ncbi.nlm.nih.gov/pmc/articles/ PMC5455626/.

Mahieu, A., Lenormand, H., Leblanc, N., Vive, A. (2015) $100 \%$ Biobased particleboards based on new agricultural wastes. Conference: First International Conference on Bio-based Building Materials - ICBBM2015, At Clermont-Ferrand France. Available from: https://www.researchgate.net/publication/282847079_100 BIOBASED_PARTICLEBOARDS_BASED_ON_NEW_AGRICULTURAL_WASTES [accessed Nov 10 2017].
Petrov, A. N., (1998) Thermal insulation materials based on straw and inorganic binders, $\mathrm{PhD}$ thesis: 05.23.05. Kazan, 178 pp.

Savytskyi M., Ozhyshchenko, O., Babenko, M., Koval, A. (2015) Integrated use of agricultural waste for the sustainable development of agricultural socio-eco-complexes as closed ecosystem, Construction, materials science, mechanical, pp. 179-186

Soldatov, D.A, Khozin, V.G. (2013) Thermal insulation materials based on straw, Construction materials and products. Bulletin of KSACU.№ 1, pp. 197-201.

Spence, R. (1997) Transformed materials, Encyclopedia of vernacular architecture of the world: Theories and principles, Book 1, Paul Oliver Cambridge University Press, pp. 260-261

Straw, K. M. (1997) Encyclopedia of vernacular architecture of the world: Theories and principles, Book 1, Paul Oliver Cambridge University Press, 1997, 232 pp. 